\title{
B cells - ontogenesis and immune memory development
}

\author{
Zuzana Nescakova and Slavomir Bystricky \\ Institute of Chemistry, Glycomed Centre, Slovak Academy of Sciences, Bratislava, Slovakia
}

\begin{abstract}
Functional diversity in the distinct developmental stages as well as anti-pathogen effectiveness and memory functionality make B cells unique and attractive object of physiology studies of the immune system. B cells are produced throughout the life of an organism, originate from the hematopoietic stem cells before birth and continue to differentiate to terminal stages. Over the past decade, there has been considerable progress in the research of all $\mathrm{B}$ cell intermediates and developmental processes. In this review, we will try to bring brief and comprehensive description of the current understanding of this fascinating topic.
\end{abstract}

Key words: B lymphocytes - Germinal centre - Immunological memory - Memory B cells - Plasma cells

\begin{abstract}
Abbreviations: Ag, antigen; BAFF, B cell activating factor; BCR, B cell receptor; Blimp-1, B lymphocyte induced maturation protein $1 ; \mathrm{CD}$, cluster of differentiation; CSR, class switch recombination; FCRL4, Fc receptor-like 4 protein; FDC, follicular dendritic cells; GC, germinal center; Ig, immunoglobulin; MALT, mucosal-associated lymphoid tissue; MHC, major histocompatibility complex; pre-B cell, precursor B cell; pro-B cell, progenitor B cell; SHM, somatic hypermutation; TACI, transmembrane activator and calcium-modulator and cyclophilin ligand interactor; TD, thymus-dependent; TI, thymus-independent; TLR, Toll-like receptor; TNF, tumor necrosis factor.
\end{abstract}

\section{Introduction}

B cells mediate the specific immune response and after interaction with an antigen, they differentiate to plasma cells producing high quantity of specific antibodies. Memory $\mathrm{B}$ cells play a decisive role in mediating long-term protection against a wide variety of infectious diseases. They also mediate or regulate many other functions essential for immune homeostasis. B cells development can be divided into two parts: a phase of antigen independency and a phase dependent on antigen presence. The first phase is limited to the bone marrow, where precursor B cells develop with the help of stromal cells into the immature B cell stage. The final stages of development of immature B cells into mature B cells occur in peripheral lymphoid organs such as spleen. When $B$ cell encounters and recognizes an antigen by the specific receptor, it starts to proliferate and differentiate to

Correspondence to: Zuzana Nescakova, Institute of Chemistry, Glycomed Centre, Slovak Academy of Sciences, Dúbravská cesta 9, 84538 Bratislava, Slovakia

E-mail: chemnesc@savba.sk plasma or memory cell. This differentiation process is fully dependent on the antigen presence.

\section{B cell maturation}

In an organism, the B cells appear for the first time at the embryonic stage and they maturate in the yolk sack, later in liver, and finally in bone marrow, which is the main site of maturation after the birth of an individual. Hematopoietic stem cells that have potential to generate all blood-cell lineages become restricted to the B lymphocyte lineage. Maturation of the B cells starts, when the lymphoid stem cell differentiates to the first $B$ cell stage - a progenitor B cell (pro-B cell). The pro-B cells proliferate and differentiate to precursor B cells (pre-B cells). Interactions between pre-B cells and stromal cells are required for the development to the immature B cells. Stromal cells form specific adhesive contacts with the developing B-lineage cells by interactions between cell-adhesion molecules and their ligands. In addition, they provide growth factors that stimulate lymphocyte differentiation and proliferation. Immature 
B cells undergo selection for self-tolerance and ability to survive in the peripheral lymphoid tissues. The cells that survived continuously circulate among all lymphoid tissues with lymph and blood. At this stage, they become mature $B$ cells and therefore they are called naive B cells. Generally, the differentiation comprises of six stages: early lymphoid stem stage, early pro- $B$, late pro- $B$, pre- $B$, immature $B$ and mature $B$ cell stage. The most characteristic feature of $B$ cell maturation is immunoglobulin gene segment-rearrangement and expression of cell-surface proteins (LeBien 2000; Janeway et al. 2001; Carsetti et al. 2004; Hardy et al. 2007; LeBien and Tedder 2008).

\section{B lymphocytes activation and proliferation}

Mature and fully functional B cells (effectors cells) leave the bone marrow and migrate with the help of lymph and blood to the sites with the highest probability to encounter an antigen, e.g., to the peripheral lymphoid organs. When $B$ cell with a specific receptor encounters responsive antigen, it activates and starts to proliferate and differentiate to the plasma and memory cell. This process of activation is influenced by the antigen character, cytokines presence, and signal translations. However, if the B cell does not encounter a suitable antigen, it is overcome by the apoptosis.

Resting B lymphocytes are driven into the cell cycle as a consequence of receiving a multiple signals from environment. The signals induce $B$ cell transition from $G_{0}$ to $G_{1}$ phase of the cell cycle and are called competence signals. This induces $\mathrm{B}$ cell responsiveness to progression factors. The signals that shift the cells further from $G_{1}$ phase to the $S$ phase are called progression signals and are set by the synthesis of lymphokines.

B cell must receive at least two signals for its activation. Thymus-independent (TI) antigens (Ag), which have many microbial constituents, activate $B$ cells and can induce antibody production in the absence of helper T-cells. The first signal required for B cell activation is delivered through its antigen receptor (BCR). The second signal required to activate antibody production is provided either directly by recognition of a common microbial constituent or by a non-thymus derived accessory cells in conjunction with massive cross-linking of B cell receptors. In contrast, when thymus-dependent (TD) antigens interact with BCR, only weak competence signal is produced and the next competence signal required is provided by the interaction of CD40 with B cells and its ligand CD40L expressed on the activated cognate Th-lymphocytes. After the activation by both signals, the B lymphocytes express receptors for the lymphokines. The binding of lymphokines represents second progression signal for B cells.

After the interaction of naive B lymphocyte with an antigen and other cells in the lymphatic tissue (Th-lymphocytes, macrophages, dendritic cells, etc.), the B cells can mature further via two pathways: 1) by moving into extra follicular areas followed by proliferation and terminal differentiation into short-lived plasma cells while secreting antibodies, which provide the first wave of defense against invading pathogens; 2 ) by migrating towards the primary follicle (cells aggregate in the secondary lymphatic organs) followed by proliferation and formation of the germinal center (GC). The mechanisms responsible for this fatal decision may be the high affinity of BCR for the foreign antigen, the rate of antigen-receptor engagement and co-stimulatory signals received from T-cells. The germinal center is a result of active $B$ cells proliferation and appears around 1-3 weeks after the TD antigen attacks to the organism. It is the site of robust proliferation and differentiation of B lymphocytes. Proliferating B lymphocytes that lack surface immunoglobulin (Ig) are called centroblasts. These cells migrate to the particular extremity of the center, stay put tightly and create so-called dark zone. Large centroblasts exit the cell cycle, re-express Ig surface and change to small centrocytes that migrate to the basal light zone, which is rich of follicular dendritic cells (FDCs) and antigen specific Th-lymphocytes. The centrocytes that do not recognize the specific antigen die by apoptosis. Surviving centrocytes enter the apical light zone, where they present antigen on their class II MHC (major histocompability complex) to the Th-cells. B cells compete for binding antigen on FDCs and then depend on receiving signals from Th-lymphocytes to survive and differentiate into plasma or memory cells (Noelle and Snow 1991; Janeway et al. 2001; McHeyzer-Williams 2003; McHeyzer-Williams and McHeyzer-Williams 2005; Wang and Carter 2005; Wood 2006; Allen et al. 2007).

\section{Differentiation of B lymphocytes}

Within germinal center, several molecular processes take place, which are necessary for differentiation of B lymphocytes and also for the evolution of long-lived immunity: the affinity maturation of the antibody, antibody class switch recombination, and differentiation of $\mathrm{B}$ cells into plasma and memory cells.

An affinity is the thermodynamic parameter that is quantified by the strength of antibody - antigen bond. The affinity maturation is extremely effective, that means that affinity progressively increases and may result in a 100- to 100000 -fold increase of its initial value. Affinity maturation reflects the process of somatic hypermutation (SHM) of Ig genes and the subsequent selection of resulting high-affinity $\mathrm{B}$ cells that occur in the germinal center. The $\mathrm{V}, \mathrm{D}$, and J genes for immunoglobulin chains rearrange and consequently, the main mutation occurs in the hypervariable regions. The point mutations, deletions, and insertions continue with much 


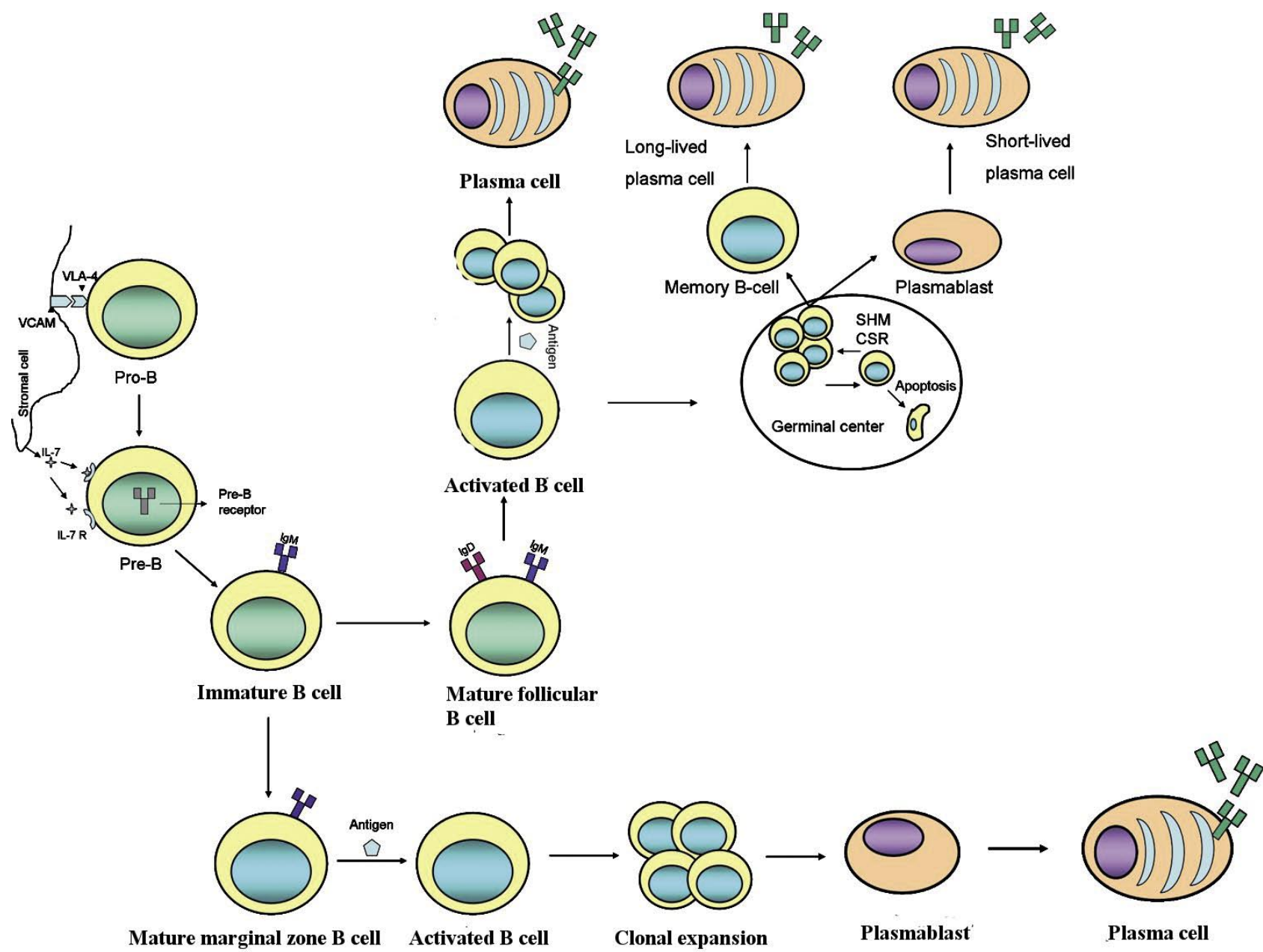

Figure 1. Mature B cells become activated in secondary lymphoid tissue after interaction with Ag. This process gives rise to the generation of plasma cells and the generation of long-lived memory B cells. Ag-specific naive B cells can differentiate within secondary lymphoid tissue into short-lived low-affinity antibody secreting plasma cells or undergo a rapid proliferative phase known as the germinal center reaction (a TD phase in which SHM and CSR occur). A small fraction of these B cells survives the reaction and proceeds to form either memory B cells or high-affinity antibody secreting plasma cells. When memory B cells are re-activated by specific Ag, they quickly respond to cognate Ag, proliferate and differentiate into the long-lived high-affinity antibody producing plasma cells. This process is less complicated, more rapid and more robust. Ag, antigen; CSR, antibody class switch recombination; IL-7, interleukin 7 (hematopoietic growth factor); IL-7R, receptor pre IL-7; pre-B, precursor B cell; pro-B, progenitor B cell; SHM, somatic hypermutation; VCAM, vascular cell adhesion molecule; VLA-4, very late antigen 4 .

higher mutation speed than the regular cells. Some cells can accumulate up to 20 mutations in their Ig genes. However, this random process generates not only high affinity cells. All cells undergo positive high-affinity cloned selection in the light zone of germinal center. The low-affinity centrocytes die by apoptosis and the selected cells expressing mutated Ig genes that code for higher affinity Ig surface competes more successfully for antigen go on to develop as effectors and memory cells. The high-affinity cells clonally expand and affinity of the antibodies progressively increases with the time passed from the encounter with antigen.
The rearrangement of VDJ-gene segment occurs in the process of the antibody class switch recombination (CSR) during the centroblast/centrocyte differentiation stage. DNA recombination allows gene moves (in the switch region) and $\mathrm{B}$ cells to be able to change the heavy chain constant region of its antibody while keeping the same heavy chain variable region and light chain intact. In this way, the specificity of antibody is identical, but the effector function is different. During class switch, B cells stop expressing IgM and $\operatorname{IgD}$ on their surface and express another class of antibody. Class switching is regulated by the B- and T-lymphocytes 
contact, type of differentiation, cytokines and site microenvironment.

After pernancy of specific signals, the centrocytes with high affinity receptors differentiate to the plasma or memory cells. IL-1 and CD23 synthesized by the follicular dendritic cells induce the generation of plasma cells secreting antibodies in high amounts. Memory cells are generated after the interaction of CD40 of centrocyte with membrane CD40L of the activated Th-lymphocytes. The antibody class switch can occur also during differentiation to the plasma or memory cells (Janeway et al. 2001; Campos and Godson 2003; Kelly et al. 2005; McHeyzer-Williams and McHeyzer Williams 2005; Ollila and Vihinem 2005; Wood 2006; Tangye and Tarlinton 2009).

\section{Immunological memory}

The ability of the immune system to remember a previous encounter with the specific antigen and the re-exposure response with a higher kinetics and efficiency than the first one is a fundamental feature of the specific (adaptive, acquired) immunity of higher vertebrates. The second antibody response is quicker, has a higher magnitude and is qualitatively different from the primary immune response. The immunological memory is a basis for the vaccination against infectious diseases (Pulendran and Ahmed 2006). Successful vaccines rely on the generation of protective antibody level. Protection is relative to a particular pathogen and may be mediated by preformed antibodies, by antibodies that are rapidly produced by antibody-secreting cells derived from proliferating memory B cells or by a combination of both (Lanzavecchia et al. 2006). B lymphocytes contribute to the generation of immunological memory by differentiation to the two different cell populations at the primary immune response. One of the populations is a group of long-lived plasma cells that continue to synthesize and secrete specific antibodies long time after removal of the antigen from an organism. Plasma cells represent compartments of effector memory (Sanz et al. 2008). Memory B cells are the second population, which represents compartments of central memory. On the other hand, "central" memory B cells could play important effector and regulatory functions e.g. Ag presentation, $\mathrm{T}$ cell and dendritic cell regulation and cytokine production (Sanz et al. 2008). Memory B cells are able to proliferate after re-encounter with the antigen and further differentiate to the plasma cells. This way the memory B cells markedly accelerates the time needed for synthesis of specific preventive antibodies (McHeyzer-Williams 2003). The ability of naive B lymphocytes to differentiate to the plasma and memory cells makes the rationale behind of majority currently used vaccines (Tangye and Tarlinton 2009). In some cases (for example individuals after smallpox vaccination) antigen-specific antibodies, as well as antigen- specific memory B cells are still detectable in the peripheral blood 50 years after immunizations (Crotty et al. 2003). Two distinct mechanisms that can contribute to sustain serum antibody are identified: the first mechanism is the longevity of plasma cells and second one is continuous antigenic stimulation by persisting antigen (Lanzavecchia et al. 2006). Despite the long-lived nature of some plasma cells, continued differentiation of memory B cells plays a major role in humoral memory (Barrington et al. 2002). Both short-term and long-term serological memories could be defined. The short-term memory is mediated by the antigen-driven production of short-lived and long-lived plasma cells, whereas the long-term memory is mediated by antigen-independent homeostatic activation of all memory B cells leading to a sustained production of plasma cells of all memory specificities (Lanzavecchia et al. 2006; Radbruch et al. 2006).

\section{Plasma cells}

Plasma cells represent non-dividing, terminally differentiated and immobile antibody-secreting cells of the B cell lineage. B lymphocyte induced maturation protein 1 (Blimp-1) is a master regulator of the terminal differentiation into antibody secreting plasma cells (Turner et al. 1994; Shinal et al. 2000; Kallies and Nutt 2007). Blimp-1 directly represses transcription factors that regulate several important gene programs: essential genes responsible for handling stress associated with huge protein production, folding and secretion (Xbp-1), promote proliferation (Bcl6, c-myc) and many others (Pax5, CTIIA etc.) (Shapiro-Shelef et al. 2005; Tarlinton et al. 2008). Number of plasma cells increase in the presence of stimuli such as IL-10, SAC plus IL-2, IL-4 plus CD40 signaling, IL-21, CD27-CD70 interaction (Radbruch et al. 2006; Schmidlin et al. 2009). The plasma cells are morphologically adapted for the effective secretion of antibodies. They have eccentrically positioned nucleus, numerous mitochondria, extensive rough endoplasmic reticulum and Golgi apparatus. The expression of Ig mRNAs increases 6-12 fold while the expression of surface Ig's decrease, since plasma cells produce only soluble antibodies (Ollila and Vihinem 2005). We are able to distinguish among populations of the short-living and long-living plasma cells. Under usual circumstances, terminally differentiated antibody secreting plasma cells are not present in the peripheral blood. This is not true only at low frequency - 1:10 million peripheral blood mononuclear cells (Kelly et al. 2005). Some of them maintain their active state dwelling in the lymphatic tissue. Plasma cells localized in the spleen and lymph nodes are mainly short-lived cells that produce antibodies during a few weeks only. Long-lived plasma cells migrate to the bone marrow, where they produce antibodies for many months, even years (Wood 2006). Moreover, plasmablasts are cells of $\mathrm{B}$ cell lineage that secrete functional antibodies, but opposed 
to the plasma cells, they are still able to divide. Plasmablasts can develop from any type of activated B cells (such as naive, marginal, follicular, germinal-centre, memory) but it is not clear whether plasmablasts of all of these origins are competent to become long-living plasma cells (Radbruch et al. 2006). The developmental details of plasmablast transition to a plasma cell are not fully understood (Tarlinton et al. 2008). Besides the different proliferation, plasmablasts have also higher expression of MHC molecules and preserve their ability to migrate. In turn, the maturation to the plasma cell is connected with a decline of proliferation, mobility and MHC expression. There is a theory that explains that the long-lived plasma cells can be differentiated only from the memory B cells (Blink et al. 2005; Odendahl et al. 2005; Radbruch et al. 2006). The longevity of plasma cells in the bone marrow is dependent on many distinct signals accessible in a specific microenvironment and a molecular competence to respond to these signals. The complete mechanism of these events is not fully known yet. The plasma cells survived ex vivo only for a couple of days, even though they were supplied with specific signals (Radbruch et al. 2006; Tarlinton et al. 2008).

\section{Memory cells}

Memory B lymphocytes are long-lived cells present in the organism long time after pathogen elimination. These cells divide very slowly, express surface Igs but do not secrete antibodies at a high rate. Some of them reside in the germinal center in the mantle zone, the others leave the germinal center and circulate in the organism. The memory cells undergo the somatic hypermutation as well as antibody class switch. They express high-affinity membrane Igs such as $\mathrm{IgG}, \mathrm{IgA}$ and $\operatorname{IgM}$. However, IgD disappeared from the surface in contrast to the naive lymphocytes (McHeyzer-Williams 2003). Persisting antigen, certain cytokine or toll-like receptor signals may drive memory $B$ cells to differentiate into long-lived plasma cells, which are the source of serum antibodies. In this way, memory B cells help to protect the host from invading pathogens by maintaining persistent levels of Ag-specific serum antibodies and generating rapid antibody responses upon re-exposure to Ag (Chappell and Jacob 2006). After the second exposure to the same antigen during recirculation, the memory cells are faster in the differentiation to plasma cells that secrete high-affinity antibodies IgG, IgA and IgE (Wood 2006). Together with kinetics of secretion, the quality of antibodies (e.g. the isotype, affinity and anti-pathogen activity) is important (Kelly et al. 2005). It was described that there is a striking correlation between the frequency of antigen-specific B cells in the memory pool and the antigen-specific IgG levels for different antigens in sera from individuals following vaccination (Bernasconi et al. 2002; Lanzavecchia et al. 2006; Rohner et al. 2008; Cao et al. 2010). Memory cells are larger in comparison to the naive $\mathrm{B}$ lymphocytes and express more co-stimulation, activation and adhesive molecules (e.g. CD80, CD86, CD95, CD54). CD27 is the characteristic differentiation antigen that is generated by a majority of human memory cells (Klein 1998; Agematsu et al. 2000). However, there are many papers describing the existence of memory cell populations that do not express CD27, mainly population of memory B cells in mice (Xiao et al. 2004; Steiniger et al. 2005; Küppers 2008; Moens et al. 2008; Tangye and Tarlinton 2009). Consequently, the memory B lymphocytes are characterized by the morphology, phenotype (e.g. CD23- $\mathrm{CD} 27^{+}$, $\mathrm{CD}^{+} 0^{+}, \mathrm{CD} 6^{+}, \mathrm{CD}^{+} 5^{+}$), adhesive molecules, molecular characteristics (e.g. somatic hypermutation, class switch), and by physiological characteristics (e.g. anatomical location, longevity and recirculation).

The persistence of memory B cells is quite well documented and it has been suggested that memory $B$ cells reside in the sites of Ag drainage such as marginal zones of lymph nodes, spleen and bone marrow. However, recent findings suggest that antigen specific memory $B$ cells preferably reside in the secondary lymphatic organs and, in small amounts, in peripheral blood but not in the bone marrow (Cao et al. 2010).

\section{Heterogeneity of memory B lymphocytes}

The diversity of memory B cell populations is hampered by pre-conceived notions of their surface phenotype, function, cellular and anatomical origin (Sanz et al. 2008).

The nature and origin of $\mathrm{CD} 27^{+} \mathrm{IgM}^{+} \mathrm{IgD}^{+}$is a subject of dispute (Kruetzman et al. 2003; Weller et al. 2004; Tangye and Good 2007; Seifert and Küppers 2009). It was proposed, that $\mathrm{CD}_{27}{ }^{+} \operatorname{IgM}^{+} \operatorname{IgD}^{+}$(as well as IgM-only B cells) are circulating in the marginal zone of unswitched memory B cells which develop outside of GC (germinal center), but still express mutated Ig (White and Gray 2000; Tangye et al. 2003; Sanz et al. 2008). In another hypothesis, $C D 27^{+} \operatorname{IgM}^{+} \operatorname{IgD}^{+}$(as well as IgM-only B cells) carry, like class-switched memory $\mathrm{B}$ cells, mutations in the Bcl6 gene as a genetic trait of a GC experience (Seifert and Küppers 2009). The lower mutation load of these cells, as compared with class-switched memory $\mathrm{B}$ cells, may imply that the antibodies produced by these cells are of lower affinity that the IgG antibodies. Moreover, these memory B cells may serve as a flexible memory B cell reservoir that may re-enter GC upon encounter with the same or similar antigen to undergo further affinity maturation (Seifert and Küppers 2009). CD27 ${ }^{+} \operatorname{IgM}^{+} \operatorname{IgD}^{+}$represent a heterogeneous population of $\mathrm{B}$ cells that have specialized functions during distinct stages of development (Shi et al. 2003; Tangye and Tarlinton 2009).

IgG is considered a marker of B cell memory and through its intracytoplasmic tail confers the signals necessary for long-term survival. $\operatorname{IgM}^{+}$and $\operatorname{IgG}^{+} \mathrm{B}$ cell memory subsets 
have distinct differentiation potential and different effector functions. After a challenge, the $\mathrm{IgG}^{+}$subset has immediate effector and protective functions, which are a hallmark of B cell memory but seems to have little capacity to reinitiate a germinal center response. The contribution of the $\operatorname{IgM}^{+}$ subset by its rapid mobilization and switching to IgG1 ensures replenishment of the memory pool from antigenexperienced precursors and thus an effector contribution delayed to following encounter with the antigen (Dogan et al. 2009).

Subpopulation of $\mathrm{IgG}^{+}$B lymphocytes occurring in tonsils, spleen and peripheral blood represents the group of cells which do not express the differentiation antigen CD27 (Fecteau et al. 2006; Küppers 2008). This subpopulation of B lymphocytes differs from $\mathrm{CD} 27^{+}$memory B lymphocytes by the expression of IgG subclasses. As the $\mathrm{CD} 27^{+} \mathrm{IgG}^{+}$ B lymphocytes express IgG1, IgG2 and IgG3, the cells $\mathrm{CD}^{2} 7^{-} \mathrm{IgG}^{+}$preferentially express IgG1 and IgG3 subclasses (Fecteau et al. 2006). These cells are derived from extrafollicular response or from incomplete germinal center reactions. Alternatively, they could represent the progeny of activated $\mathrm{CD} 27^{+}$memory B cells that have lost CD27 expression (Sanz et al. 2008).

The inspection of lymphoid tissue of human tonsils revealed another subpopulation of $\mathrm{CD} 27^{-}$memory B lymphocytes on the basis of the inhibitory receptor Fc-receptor-like 4 expression (FCRL4) (Ehrhardt et al. 2005; Polson et al. 2006; Küppers et al. 2008). More than $60 \%$ of those cells express IgG and around $25 \%$ of them also express IgA in contrast with $\mathrm{CD}_{2} 7^{-}$cells in periphery blood (Ehrhardt et al. 2005). Localization of FCRL $4{ }^{+} \mathrm{CD} 27^{-}$memory B lymphocytes is probably restricted to MALT (mucosal-associated lymphoid tissue) since the cells were detected neither in bone marrow, spleen, lymph nodes nor in peripheral blood (Ehrhardt et al. 2005; Polson et al. 2006). Due to the strategic location and ability of very quick differentiation to the plasma cells, they play important roles in mucosal humoral immune response (Tangye and Tarlinton 2009).

Many subpopulations of memory B lymphocytes were detected in humans as well as in mice. The exact relationship between distinct subpopulations of B lymphocytes as well as their contribution to the generation and maintenance of long-lasting humoral immune response is a subject of future explorations.

\section{Mechanisms assuring rapidity of secondary immune re- sponse}

One of the most important features of memory cells is their ability to react quickly after re-challenge by the antigen that initiated their generation. This attribute could be facilitated by several mechanisms.
To develop effector function, both naive and memory cells require T-cell help. However, memory B cells proliferate in response to lower amounts of antigen and require fewer Th-cells or less lymphokines (Campos and Godson 2003). In addition, a frequency of precursor antigen-specific memory $\mathrm{B}$ cells is higher than that of antigen-binding naive $\mathrm{B}$ cells (McHeyzer-Williams and McHeyzer-Williams 2005; Bhattacharya et al. 2007).

The presence of antibody, which is higher than that at the time of first encounter, reduces the threshold for B cell activation by cross-linking CD21 to the BCR. B cells in marginal-zone also up-regulate the expression of CD21 (MacLennan et al. 2000).

Because of changes in the structure of the antigen receptor, as a consequence of somatic mutation of Ig genes during development in germinal center, memory B cells express mutated BCR with higher affinity for antigen than the naive population.

Strategic localization of memory B cells is very important. This distribution upgrades the possibility of antigen encounter and accelerates a new response. The cells are located in the marginal zone of spleen, thus are perfused by the blood, and consequently have direct access to antigen in the blood. Spleen is the principal site of memory cells accumulation and in comparison with the periphery bloodstream, there are up to 100-times more antigen-specific memory B cells (Tangye and Tarlinton 2009). Memory B cells in the tonsils are located in the mucosal epithelium that lines the tonsilar crypts which are directly open to the oropharynx, in Peyer's patches and lie under the epithelium with antigen-transmitting M cells, etc. (MacLennan et al. 2000).

Memory B cells constitutively express co-stimulation molecules CD80 and CD86 (Liu et al. 1995; Anderson et al. 2007), as well as Toll-like receptors (such as TLR2, TLR6, TLR7, TLR9, TLR10). When triggered by the corresponding TLR agonist (e.g. CpG or R848) memory B cells proliferate and differentiate to antibody-secreting cells. By contrast, naive cells do not constitutionally express TLRs and are not able to response directly to the microbial products (Bernasconi et al. 2003). While human naive B cells require three signals to be activated, two of which are antigen specific, memory $B$ cells can be activated to proliferate and differentiate in an antigen-independent fashion by microbial products, cytokines and in the absence of BCR stimulation via TLRs or bystander T-cell help (Lanzavecchia et al. 2006).

After serotype class switching, the cytoplasmic domain of Ig chains acquire different biochemical properties that allow the cells to express both IgM and IgG or chimeric $\mathrm{IgM} / \mathrm{IgG}$ molecules. IgG is considered a marker of B cell memory and confer, through its intra-cytoplasmic tail, the signals necessary for improved secondary response and long-term survival (Wakabayashi et al. 2002; Dogan et al. 2009). Cytoplasmic domain of chimeric IgM/IgG molecules 
is derived from IgG. This consequence explains the ability of $\mathrm{IgG}^{+}$and chimeric IgM/IgG B cells to secret more than 100fold more Ig after re-challenge with the specific antigen in comparison with $\operatorname{IgM}^{+}$B cells (Horikawa et al. 2007; Tangye and Tarlinton 2009).

Besides morphological, physiological and phenotype differences, the gene expression differs between memory and naive $B$ cells. Memory $B$ cells increase expression of CD40-inducible factors such as Bcl-2, A1 and Mcl-1, which protect them from antigen-receptor-mediated apoptosis (Craxton et al. 2000). This correlates with their improved survival (Tangye and Tarlinton 2009).

In comparison with naive B cells, memory B cells decrease expression of negative regulators of the cell cycle as p21, WAF-1, KLF4, KLF9 and PLZF, and increase the level of pro-proliferative cyclin E1 genes (Ehrhardt et al. 2008; Good et al. 2009). Further, increase expression of components of intra-cellular signaling pathways - adenosine receptor 2A and isoforms of protein kinase C (Tomayko et al. 2008; Tangye and Tarlinton 2009). Memory B cells up-regulate leukemia inhibitory factor receptors that are essential for embryonic stem cell self-renewal (Tomayako et al. 2008). The function of genes specific for memory B lymphocytes is not fully understood yet.

A small number of memory cells are detectable in an organism for many months even years. The mechanisms responsible for longevity of memory B lymphocytes are not fully understood. Earlier, it was predicted that surviving of memory cells is firmly restricted to the presence of inducing antigen in an organism (Gray and Skarvall 1988). Currently, it is thought that the presence of antigen is not an essential condition (Maruyama et al. 2000). In addition, a persistent support from Th-lymphocytes is not required (Vieira and Rajewsky 1990). Approximately $2 \%$ of human memory $B$ cells divide every day and mouse memory B cells proliferate and differentiate in the absence of antigen (Lanzavecchia et al. 2006).

One of existing hypothesis says that the surviving is supported by B cell activating factor (BAFF) belonging to the TNF family (Tangye et al. 2006). This statement supports the outcome that the presence of BAFF is necessary for the differentiation of B lymphocytes to mature B lymphocytes in mice. Similarly, longevity of memory cells is supported by the finding that memory cells express BAFF-R and TACI (transmembrane activator and calcium-modulator and cyclophilin ligand interactor) receptors for BAFF. Individuals with the mutation in TACI gene have lower ability to differentiate B lymphocytes to the terminal stage (Tangye and Tarlinton 2009). However, there are findings that contradict these claims (Benson et al. 2008).

Longevity of memory B cells may be mediate through the expression of higher levels of antiapoptotic factors $\mathrm{Bcl} 2$ and Birc6 (Bhattacharya et al. 2007). Mechanism responsible for the longevity of memory B lymphocytes is the topic for future investigations.

\section{Concluding remarks}

Important feature of the immune system is its ability to remember an encounter with a pathogen, what assures better and long-lasting defense again pathogens. Recently, the understanding of the role of B cells in host defense system has been achieved. The interaction and cooperation of cells implicated in immune memory response and new subsets of memory B cells and mechanisms assuring rapidity of secondary immune response have been identified. During the past decade, many micro-environmental factors and initiation signals regulating development of B cell populations have been identified. However, their mutual relationships and coordination have to be still revealed. Knowledge of these critical parameters promoting memory and plasma cells induction and maintenance will admittedly potentiate the possibility of the effective active interventions. It is the key achievement to be completed in the future for effective immune-prevention development.

Acknowledgements. This work was supported by the grants APVV003206 and VEGA 2/0040/10.

\section{References}

Agematsu K., Hokibara S., Nagumo H., Komiyama A. (2000): CD27: a memory B cell marker. Immunol. Today 21, 204-206 doi:10.1016/S0167-5699(00)01605-4

Allen D. C, Okada T., Cyster J. G. (2007): Germinal-center organization and cellular dynamics. Immunity 27, 190-202 doi:10.1016/j.immuni.2007.07.009

Anderson S. M., Tomayko M. M., Ahuja A., Haberman A. M., Shlomchlik M. J. (2007): New markers for murine memory B cells that define mutated and unmutated subsets. J. Exp. Med. 204, 2103-2114 doi:10.1084/jem.20062571

Barrington R. A., Pozdnyakova O., Zafari M. R., Benjamin C. D., Carroll M. C. (2002): B lymphocyte memory: role of stromal cell complement and FcyRIIB receptors. J. Exp. Med. 196, 1189-1199 doi:10.1084/jem.20021110

Benson M. J., Dillon S. R. Castigli E., Geha R. S., Xu S., Lam K. P., Noelle R. J. (2008): Cutting edge: the dependence of plasma cells and independence of memory B cells on BAFF and APRIL. J. Immunol. 180, 3655-3659

Bernasconi N. L., Traggiai E., Lanzavecchia A. (2002): Maintenance of serological memory by polyclonal activation of human memory B cells. Science 298, 2199-2202 doi:10.1126/science.1076071 
Bernasconi N. L. Onai N., Lanzavecchia A. A. (2003): A role for Tolllike receptors in acquired immunity: up-regulation of TLR9 by $\mathrm{BCR}$ triggering in naive $\mathrm{B}$ cells and constitutive expression in memory B cells. Blood 101, 4500-4504 doi:10.1182/blood-2002-11-3569

Bhattacharya D., Cheach M. T., Franco C. B., Hosen N., Pin C. L., Sha W. C., Weissman I. L. (2007): Transcriptional profiling of antigen-dependent murine $\mathrm{B}$ cell differentiation and memory formation. J. Immunol. 179, 6808-6819

Blink E. J., Light A., Kallies A., Nut S. L., Hodgkin P. D., Tarlinton D. M. (2005): Early appearance of germinal center-derived memory B cells and plasma cells in blood after primary immunization. J. Exp. Med. 201, 545-554 doi: $10.1084 /$ jem. 20042060

Campos M., Godson D. L. (2003): The effectiveness and limitations of immune memory: understanding protective immune responses. Int. J. Parasitol. 33, 655-661 doi:10.1016/S0020-7519(03)00066-3

Cao Y., Gordic M., Kobold S., Lajmi N., Meyer S., Bartels K., Hildebrandt Y., Luetkens T., Ihloff A. S., Kroger N., Bokemeyer C., Atanackovic D. (2010): An optimized assay for the enumeration of antigen-specific memory B cells in different compartments of the human body. J. Immunol. Methods 358, 56-65 doi:10.1016/j.jim.2010.03.009

Carsetti R., Rosado M. M., Wardmann H. (2004): Peripheral development of B cells in mouse and man. Immunol. Rev. 197, 179-191 doi:10.1111/j.0105-2896.2004.0109.x

Chappell C. P., Jacob J. (2006): Identification of memory B cells using a novel transgenic mouse model. J. Immunol. 176, 4706-4715

Craxton A., Chuang P. I., Shu G., Harlan J. M., Clark E. A. (2000): The CD40-inducible Bcl-2 family member A1 protects B cells from antigen receptor-mediated apoptosis Cell. Immunol. 200, 56-62 doi:10.1006/cimm.2000.1616

Crotty S., Felgner P., Davies H., Glidewell J., Villarreal L., Ahmed R. (2003) Cutting edge: long-term B cell memory in humans after smallpox vaccination. J. Immunol. 171, 4969-4973

Dogan I., Barbara B., Vilmont V., Delbos F. Megret J., Storck S., Reynaud C. A., Weill J. C. (2009): Multiple layers of B cell memory with different effector functions. Nat. Immunol. 10, 1292-1299 doi:10.1038/ni.1814

Ehrhardt G. R., Hijikat A., Kitamura H., Ohara O., Wang J. Y., Cooper M. D. (2008): Discriminating gene expression profiles of memory B cell subpopulations. J. Exp. Med. 205, 1807-1817 doi:10.1084/jem.20072682

Ehrhardt G. R., Hsu J. T., Gartland L., Leu Ch. M., Zhang S., Davis R. S., Cooper M. D. (2005): Expression of the immunoregulatory molecule FcRH4 defines a distinctive tissue-based population of memory B cells. J. Exp. Med. 202, 783-791 doi:10.1084/jem.20050879

Fecteau J. F., Cote G., Neron S. (2006): A new memory CD27-IgG $\mathrm{B}+$ cell population in peripheral blood expressing $\mathrm{VH}$ genes with low frequence of somatic mutation. J. Immunol. 177, 3728-3736

Good K. L. Avery D. T., Tangye S. G. (2009): Resting human memory B cells are intrinsically programmed for enhanced survival and responsiveness to diverse stimuli compared to naive B cells. J. Immunol. 182, 890-901

Gray D., Skarvall H. (1988): B cell memory is short-lived in the absence of antigen. Nature 336, 70-73 doi:10.1038/336070a0

Hardy R. R., Kincade P. W., Dorshkind K. (2007): The protean nature of cells in the B lymphocyte lineage. Immunity 26, 703-714 doi:10.1016/j.immuni.2007.05.013

Horikawa K., Martin S. W., Pogue S. L., Silver K., Takatsu K., Goodnow C. C. (2007) Enhancement and suppression of signaling by the conserved tail of IgG memory-type B cell antigen receptors. J. Exp. Med. 204, 759-769 doi:10.1084/jem.20061923

Janeway C. A. Jr., Travers P., Walport M., Shlomchik M. J. (2001): Immunobiology. Garland Publishing, New York

Kallies A., Nutt S. L. (2007) Terminal differentiation of lymphocytes depends on Blimp-1. Curr. Opin. Immunol. 19, 156-162 doi:10.1016/j.coi.2007.01.003

Kelly D. F., Pollard A. J., Moxon E. R. (2005) Immunological memory: the role of $\mathrm{B}$ cells in long-term protection against invasive bacterial pathogens. JAMA 294, 3019-3023

Klein U., Rajewsky K., Küppers R. (1998): Human immunoglobin IgM IgD peripheral blood B cells expressing the CD27 cell surface antigen carry somatically mutated variable region genes: $\mathrm{CD} 27$ as a general marker for somatically mutated memory B cells. J. Exp. Med. 188, 1679-1689 doi:10.1084/jem.188.9.1679

Kruetzmann S., Rosado M. M., Weber H., Germing U., Tournilhac O., Peter H. H., Berner R. (2003): Human immunoglobulin M memory B cells controlling Streptococcus pneumonie infections are generated in the spleen. J. Exp. Med. 197, 939-945 doi:10.1084/jem.20022020

Küppers R. (2008): Human memory B cells:memory B cells of a special kind. Immunol. Cell. Biol. 86, 635-636 doi:10.1038/icb.2008.59

Lanzavecchia A., Bernasconi N. L., Traggiai E., Ruprecht C. R., Corti D., Sallusto F. (2006): Understanding and making use of human memory B cells. Immunol. Rev. 211, 303-309 doi:10.1111/j.0105-2896.2006.00403.x

LeBien T. W. (2000): Fates of human B-cell precursors. Blood 96, 9-22

LeBien T. W., Tedder T. F. (2008): B lymphocytes: how they develop and function. Blood 112, 1570-1580 doi:10.1182/blood-2008-02-078071

Liu Y. J., Barthelemy C., Bouteiller O., Arpin C., Durand I., Banchereau J. (1995): Memory B cells from human tonsils colonize mucosal epithelium and directly present antigen to $\mathrm{T}$ cell by rapid up-regulation of B7-1 and B7-2. Immunity 2, 239-248 doi:10.1016/1074-7613(95)90048-9

MacLennan I. C., Vinuesa C. G., Casamayor-Palleja M. (2000): B cell memory and the persistence of antibody responses. Philos. Trans. R. Soc. Lond. B., Biol. Sci. 355, 345-350 doi:10.1098/rstb.2000.0571

Maruyama M., Lam K. P., Rajewsky K. (2000): Memory B cell persistence is independent of persisting immunizing antigen. Nature 407, 636-664 doi: $10.1038 / 35036600$ 
McHeyzer-Williams M. (2003): B cells as effectors. Curr. Opin. Immunol. 15, 354-361 doi:10.1016/S0952-7915(03)00046-3

McHeyzer-Williams L. J., McHeyzer-Williams M. G. (2005): Antigen-specific memory B cell development. Annu. Rev. Immunol. 23, 487-513 doi:10.1146/annurev.immunol.23.021704.115732

McHeyzer-Williams L. J., Malherbe L. P., McHeyzer-Williams M. G. (2006): Checkpoints in memory B cell evolution. Immunol. Rev. 211, 255-268 doi:10.1111/j.0105-2896.2006.00397.x

Moens L., Wuyts M., Meyts I., Boeck K., Bossuyt X. (2008): Human memory B lymphocyte subsets fulfill distinct roles in the anti-polysaccharide and anti-protein immune response. J. Immunol. 181, 5306-5312

Noelle R. J., Snow E. C. (1991): T helper cell-dependent B cell activation. FASEB J. 5, 2770-2776

Odendahl M., Mei H., Hoyer B. F., Jacobi A. M., Hansen A., Muehlinghaus G., Berek C., Hiepe F., Manz R., Radbruch A., Dörner T. (2005): Generation of migratory antigen-specific plasma blasts and mobilization of resident plasma cells in a secondary immune response. Blood 105, 1614-1621

doi:10.1182/blood-2004-07-2507

Ollila J., Vihinen M. (2005): B cells. Int. J. Biochem. Cell Biol. 37, 518-523 doi:10.1016/j.biocel.2004.09.007

Polson A. G., Zheng B., Elkins K., Chang W., Du C., Dowd P., Yen L. (2006): Expression pattern of the human FcRH/IRTA receptors in normal tissue and in B-chronic lymphocytic leukemia. Int. Immunol. 18, 1363-1373 doi:10.1093/intimm/dxl069

Pulendran B., Ahmed R. (2006): Translating innate immunity into immunological memory: implications for vaccine development. Cell 124, 849-863

Radbruch A., Muehlinghaus G., Luger E. O., Inamine A., Smith K. G. C., Dörner T., Hiepe F. (2006): Competence and competition: the challenge of becoming a long-lived plasma cell. Nat. Rev. Immunol. 6, 741-750 doi: $10.1038 /$ nri1886

Rohner G. B., Snape M. D., Kelly D. F., John T., Morant A., Yu L. M., Borkowski A., Ceddia F., Borrow R., Siegrist C. A., Pollard A. J. (2008): The magnitude of the antibody and memory B cell responses during priming with a protein-polysaccharide conjugate vaccine in human infants is associated with the persistence of antibody and the intensity of booster response. J. Immunol. 180, 2165-2173

Sanz I., Wei Ch., Lee F., Anolik J. (2008): Phenotypic and functional heterogeneity of human memory B cells. Semin. Immunol. 20, 67-82 doi:10.1016/j.smim.2007.12.006

Seifert M., Küppers R. (2009): Molecular footprints of a germinal center derivation of human $\operatorname{IgM}+(\mathrm{IgD}+) \mathrm{CD} 27+\mathrm{B}$ cells and the dynamics of memory B cell generation. J. Exp. Med. 206, 2659-2669 doi:10.1084/jem.20091087

Shapiro-Shelef M., Lin K. L., Savitsky D., Liao J., Calame K. (2005): Blimp-1 is required for maintenance of long-lived plasma cells in the bone marrow. J. Exp. Med. 202, 1471-1476 doi:10.1084/jem.20051611
Shi Y., Agematsu K., Ochs H. D., Sugane K. (2003): Functional analysis of human memory B cell subpopulations: $\operatorname{IgD}+\mathrm{CD} 27+$ $\mathrm{B}$ cells are crucial in secondary immune response by producing high affinity IgM. Clin. Immunol. 108, 128-137 doi:10.1016/S1521-6616(03)00092-5

Shinal S. M., Gonzales-Fernandez M., Noelle R. J., Waldschmidt T. J. (2000): Identification of murine germinal center B cell subsets defined by the expression of surface isotypes and differentiation antigens. J. Immunol. 164, 5729-5738

Schmidlin H., Diehl S. A., Blom B. (2009): New insights into the regulation of human B cell differentiation. Trends Immunol. 30, 277-285 doi:10.1016/j.it.2009.03.008

Steiniger B., Timphus E. M., Jacob R., Barth P. (2005): CD27+ B cells in human lymphatic organs: re-evaluating the splenic marginal zone. Immunology 116, 429-442

Tangye S. G., Avery D. T., Deenick E. K., Hodgkin P. D. (2003): Intrinsic differences in the proliferation of naive and memory human B cells as a mechanism for enhanced secondary immune responses. J. Immunol. 170, 686-694

Tangye S. G., Bryant V. L., Cuss A. K., Good K. L. (2006): BAFF, APRIL and human B cell disorders. Semin. Immunol. 18, 305-317 doi:10.1016/j.smim.2006.04.004

Tangye S. G., Good K. L. (2007): Human IgM+CD27+ B cells: memory B cells or „memory“ B cells? J. Immunol. 179, 13-19

Tangye S. G., Tarlinton D. M. (2009): Memory B cells: Effectors of long-lived immune responses. Eur. J. Immunol. 39, 2065-2075 doi:10.1002/eji.200939531

Tarlinton D., Radbruch A., Hiepe F., Dörner T. (2008): Plasma cell differentiation and survival. Cur. Opin. Immunol. 20, 162-169 doi:10.1016/j.coi.2008.03.016

Tomayko M. M., Anderson S. M., Brayton C. E., Sadanand S., Steinel N. C., Behrens T. W., Shlomchik M. J. (2008): Systematic comparison of gene expression between murine memory and naive $\mathrm{B}$ cells demonstrate that memory $\mathrm{B}$ cells have unique signaling capabilities. J. Immunol. 181, 27-38

Schmidlin H., Diehl S. A., Blom B. (2009): New insights into the regulation of human B cell differentiation. Trends Immunol. 30, $277-285$ doi:10.1016/j.it.2009.03.008

Turner C. A. Jr., Mack D. H., Davis M. M. (1994): Blimp-1, a novel zinc finger-containing protein that can drive the maturation of B lymphocytes into immunoglobulin-secreting cells. Cell 77, 297-306

Vieira P., Rajewsky K. (1990): Persistance of memory B cells in mice deprived of T cell help. Int. Immunol. 2, 487-494 doi:10.1093/intimm/2.6.487

Wakabayashi Ch., Adachi T., Wienands J., Tsubata T. (2002): A distinct signaling pathway used by the IgG-containing B cell antigen receptor. Science 298, 2392-2395 doi:10.1126/science. 1076963

Wang Y., Carter R. H. (2005): CD19 regulates B-cell maturation, proliferation and positive selection in the FDC zone of murine splenic germinal centers. Immunity 22, 749-761 doi:10.1016/j.immuni.2005.04.012 
Weller S., Braun M. C., Tan B. K., Rosenwald A., Cordier C., Conley M. E., Plebani A. (2004) Human blood IgM „memory“ B cells are circulating splenic marginal zone B cells harboring a prediversified immunoglobulin repertoire. Blood 104, 3647-3654 doi:10.1182/blood-2004-01-0346

White H., Gray D. (2000): Analysis of immunoglobulin isotype diversity and IgM/D memory in the response to phenyl-oxazolone. J. Exp. Med. 191, 2209-2220

doi:10.1084/jem.191.12.2209
Wood P. (2006): Understanding Immunology, 2nd edition. Pearson Education Limited, England

Xiao Y., Hendriks J., Langerak P., Jacobs H., Borst J. (2004): $\mathrm{CD} 27$ is acquired by primed B cells at the centroblast stage and promotes germinal center formation. J. Immunol. 172, $7432-7441$

Received: June 26, 2010

Final version accepted: October 4, 2010 